\title{
Presentación al dossier Violencia, Narrativa y Moralidad
}

ste dossier contiene cuatro artículos sobre el homicidio, la manifestación más emblemática
de la violencia interpersonal, analizando narrativas de los victimarios y de actores de control
penal que permiten revisar argumentos para evaluar, juzgar y dar sentido al acto de matar. Es un abordaje de la violencia a través de relatos donde la presentación, defensa o censura de la acción frente a una audiencia, esto es, su relevancia moral, constituye el foco de atención.

Se discute desde hace tiempo si América Latina encabeza, como región, un ranking mundial de la violencia, medido por las tasas de homicidios. En este contexto, existen múltiples manifestaciones y registros sugiriendo que las formas de violencia más graves afectan a los grupos más pobres y con escaso poder de reclamo social, quienes conformarían una población intercambiable de víctimas y victimarios, con ocasión del control de territorios y mercados, de la resolución de disputas o agravios y de la confrontación, formal o informal, con agentes estatales. La reflexión sobre el sentido de dicha violencia ha sido más bien escasa, dado que predominan los indicadores epidemiológicos y las explicaciones gruesas sobre la marginación y la privación. Tampoco pareciera prosperar el análisis sobre la dinámica entre actores violentos y el sistema jurídico formal, más allá de la asumida violencia estructural y de la denuncia de un estado policial al que habría que oponer un sistema legal garantista mediante la tutela judicial. Por lo que toca al abordaje en países industrializados y centrales, donde los registros sobre la violencia interpersonal muestran baja incidencia, los análisis sobre su vinculación con la moralidad se proponen, abrumadoramente, a través de instrumentos administrados a escolares mediante pruebas $y$ escalas que conectan apreciaciones simplificadas con formas banales de desviación y agresión. La investigación sobre la violencia requiere, por consiguiente, una profundización y diversificación de enfoques, una jerarquización en función de la entidad y efectos de sus manifestaciones y un mayor énfasis en la investigación cualitativa, que permite la generación de conceptos e hipótesis novedosos así como dar la voz a sus protagonistas directos y a quienes asumen la función de contenerlos. Los artículos que forman este dossier procuran este propósito, contribuyendo a colmar una laguna interpretativa mediante el análisis de textos, de victimarios y operadores del sistema penal, colocando las narrativas dentro de una perspectiva moral que puede desafiar el consenso y la homogeneidad que dominan la literatura sobre esta materia.

Querría enfatizar en esta Presentación algunas consideraciones metodológicas y sustantivas sobre los dos términos que sostienen el análisis de los artículos aquí presentados: lo que podría 
ser llamado el continente, esto es la narrativa misma, y lo que podría ser denominado el contenido, esto es, los juicios y las apreciaciones que subyacen en los discursos de victimarios y operadores del sistema de justicia penal.

Las narrativas empleadas como fuente de acceso al significado admiten diversas formas de análisis. En una de las contribuciones de este dossier son tratadas de manera formal y secuencial (Birkbeck y Rodríguez), procurando como objetivo la identificación y la réplica de un modelo discursivo predefinido, donde el relato se segmenta en unidades diferenciadas de análisis, concediendo relevancia fundamental a la organización y coherencia del discurso mismo. Este modelo, que parte de esquemas bien definidos y articulados con investigaciones donde la pureza metodológica, la secuencia, la organización y la réplica son los elementos rectores, podría llegar a fragmentar el contenido de la argumentación en aras de la nitidez clasificatoria, percibiendo inconsistencias donde las secuencias narrativas no fluyen de manera lineal y previsible. De este modo, podría conducir a encontrar discrepancias donde acaso lo que hay es una organización distinta del relato, tal como sería la diferencia entre textos literarios de desarrollo lineal o discontinuo. En otras contribuciones (Antillano y Sepúlveda; Gabaldón), las narrativas son abordadas de manera sustantiva y fluida, a través de las cuales se procura identificar contenidos y significados más allá del orden y la secuencia. No hay categorización previa por cuanto el contenido del discurso se hace relevante en la medida en que se desarrolla libremente, y corresponde al investigador, antes que adoptar un esquema dentro un marco hipotético pre definido, reconstruir a través de la narrativa elementos relevantes para una interpretación contextualizada e integral. Los relatos judiciales, en la contribución de Monsalve-Briceño, se encuentran de algún modo en una posición intermedia, dado que las fórmulas jurídicas se repiten y tienden al estereotipo, ofreciendo menos espacio para la elaboración discursiva más allá de los enunciados normativos; sin embargo, la interpolación de los elementos de dramatización y calificación que incorporan fiscales y jueces a la tipificación e individualización de las conductas punibles, ofrecen una apertura y una visión de algún modo holística sobre el juicio moral y su alcance. En todo caso, el valor de las narrativas radica en que contraponen a esquemas simplificados y pre codificados para la evaluación moral, como escalas continuas o discretas, o dilemas con opciones cerradas, relatos más libres y expansivos, independientemente que el criterio que orienta el análisis restrinja o amplíe el significado, la riqueza y la variedad del relato. En este sentido, todas las contribuciones de este número temático procuran romper con el modelo escalar, cerrado y cuantificador de las diferencias, sustituyéndolo por un modelo interpretativo, abierto y cualificador para el abordaje de la moralidad en su relación con la transgresión violenta. Todo ello independientemente que se prefiera un procedimiento de segmentación o un procedimiento de integración. 
En lo que se refiere al contenido de juicios y apreciaciones morales, estos artículos identifican, describen y revisan las narrativas apuntando a lo generalmente aceptado y a la contraposición entre bien y mal (Birkbeck y Rodríguez; Monsalve-Briceño), o apuntando a lo divergente y a la contraposición entre sometimiento y rebeldía (Antillano y Sepúlveda; Gabaldón). El abordaje de los textos mediante parámetros más rígidos, asociados a la tipología de los accounts y a los escritos de acusaciones y sentencias, contribuye a la consistencia y homogeneidad en el eje bien/mal, que es, por cierto, la concepción predominante de la moralidad como equilibrio, de tradición aristotélica reforzada por la perspectiva kantiana. La proposición de una lectura más flexible de los relatos de los victimarios homicidas conduce al empoderamiento, la autoafirmación y el desafío a una moralidad convencional. Otra distinción observable en el tratamiento de la cuestión entre los diversos ensayos es la relativa al compromiso moral como reconocimiento de agencia frente a la negación de responsabilidad como falta de compromiso (Antillano y Sepúlveda), si bien Birkbeck y Rodríguez engloban ambas dimensiones dentro de las razones morales, lo cual permitiría agrupar como compromiso a las justificaciones y las concesiones, y como falta de compromiso a las negaciones y las excusas. También emerge en la discusión de la moralidad la distinción entre el dominio del hecho, que sería propio del discurso moral de los homicidas maduros (Antillano y Sepúlveda), como también subyace en el lenguaje y razonamiento jurídico (Monsalve-Briceño), frente a la atribución a causas externas o a la fatalidad, si bien esta conexión no excluye la aceptación de la responsabilidad, el empoderamiento y la autoafirmación como dimensiones morales (Gabaldón) o las justificaciones y excusas como relatos de significado moral (Birkbeck y Rodríguez). Finalmente, la relación entre moralidad y audiencias alternativas ha sido destacada como un componente importante para entender la representación moral, no sólo frente a la deseabilidad (Antillano y Sepúlveda) sino a la plausibilidad del relato mismo (Gabaldón). Este hallazgo y el significado que asumen figuras de referencia, control o soporte, dentro del grupo familiar aunque también extraños a él, cuestiona la prevalencia e incluso la hegemonía de códigos morales extendidos y uniformes que subyacen en otros enfoques en este dossier (Birkbeck y Rodríguez; Monsalve-Briceño).

Las contribuciones a este dossier plantean cuestiones conceptuales y metodológicas para un debate sobre el significado y la minimización de la violencia. Por un lado, permiten cuestionar la idea de moralidad como un consenso en torno a valores y principios ampliamente difundidos, incluso frente a un hecho tan dramático y jurídicamente reprobado a nivel universal como el homicidio, sobre cuyo consenso rara vez se discute, y que ha sido generalmente considerado como un caso típico de mala in se, uniformemente censurado. También contribuyen a destacar los refuerzos de conductas agresivas y los mecanismos que justifican la organización de la 
represión estatal y la extensión de su coacción dentro del ámbito de la legalidad procesal. Por otra parte destacan la importancia de las narrativas provenientes de diversas fuentes como corpus relevantes para el análisis de la construcción y sostenimiento de discursos morales, así como el valor de la investigación cualitativa que genera intuiciones, conceptos y confiere la palabra, como creadores de discursos, a los victimarios y a los agentes de control social formal, buscando la interacción y abriendo posibilidades para el análisis cruzado entre unas y otras representaciones, así como el descubrimiento de procesos de negociación de consecuencias e identidades, dentro de ese proceso de interacción. Desde el punto de vista de la política pública, ofrecen datos no usuales para profundizar diagnósticos y propuestas con la finalidad de afrontar $\mathrm{y}$, eventualmente, reducir la violencia social.

No querría finalizar esta Presentación sin destacar el esfuerzo que ha requerido abordar a los actores y documentos que conforman el corpus para la elaboración de estos artículos. Se trata de un trabajo paciente y perseverante en un entorno caracterizado por la polarización política y por el distanciamiento entre la academia y las instancias oficiales que gestionan el sistema de justicia. A ello se añada la dificultad para establecer confianza en la aproximación a actores estigmatizados, recluidos e incluso confinados en sus rutinas cotidianas, dentro o fuera de la legalidad. Todo esto ha representado desafíos importantes para el acceso, recolección de datos y preservación de la seguridad y la confidencialidad. Estos procesos justificarían, por sí mismos, una discusión aparte.

Quiero agradecer a los colegas que con entusiasmo accedieron a contribuir con este dossier, así como a todas las personas e instituciones que, manteniendo confianza en la universidad, facilitaron el acceso para recopilar datos en las condiciones más disímiles. Especialmente agradecemos a quienes resultando victimarios, judicializados o no, accedieron a compartir con nosotros sus experiencias y relatos, así como a los árbitros de Dilemas quienes contribuyeron a la versión final que ahora presentamos.

Luis Gerardo Gabaldón, organizador del dossier. 
LUIS

GERARDO

GABALDÓN

(luisgerardogabaldon@gmail.com) é professor titular de direito penal e criminologia na Universidad de los Andes (ULA, Mérida, Venezuela) e na Universidad Católica Andrés Bello (Ucab, Caracas, Venezuela). É pósgraduado em direito penal e criminologia pela Universidade de Roma "La Sapienza" (Uniroma, Itália) e graduado em direito pela ULA.

https://orcid.org/0000-0003-4264-2127 